\title{
Heavy Metal Bioaccumulation as Indicators of Environmental Pollution and Health Risks
}

\author{
Charles Mboya Matoka ${ }^{1}$, Samson Odira Omolo ${ }^{1,2}$ and Josiah Ochieng' Odalo ${ }^{2}$ \\ ${ }^{I}$ Institute of Research, Innovation and Extension (IRIE), Technical University of Mombasa (TUM), Tom Mboya \\ Avenue, P. O. Box 90420 - 80100, Mombasa, Kenya \\ ${ }^{2}$ Department of Pure and Applied Sciences, Technical University of Mombasa (TUM), Tom Mboya Avenue, \\ P. O. Box 90420 - 80100, Mombasa, Kenya
}

\begin{abstract}
The rapid increase of Mombasa City population has resulted into a significant rise in demand for decent housing. The inadequacy of planned decent housing has forced low level income households to inhabit slums around Tudor Creek along the Indian Ocean. The expansive unplanned settlement along Mombasa Island lacks basic infrastructural facilities that culminate into raw effluent discharge into the ocean. Environmental pollution present a great risk to human health, especially industrial waste water loaded with heavy metals. An investigation of anthropogenic activities and corresponding environmental pollutants was undertaken in three sites (Mikindani, Moroto and Old Town) within Tudor Creek ecosystem. Floral and faunal populations as well as heavy metal bioaccumulation varied significantly among the three sites. Floral biodiversity was dominated by mangroves that potentially acted as buffers by immobilizing heavy metals and climatic change mitigation through carbon sequestration.

The four dominant mangrove species included; Rhizophora mucronata, Sonnerata alba, Ceriops tagal and Avicennia marina, of which $R$. mucronata was the most diverse with an index of 0.75 and 0.57 at Mikindani and Moroto, respectively. C. tagal inhabited Mikindani site only and expressed diversity index of 0.33. Evaluation of heavy metal bioaccumulation among selected faunal muscles revealed significant concentrations thus acting as indicators of environmental pollution levels and health risks. Heavy metal concentrations detected in water, soil, crustacean, mollusk and fish muscles included Ti, $\mathrm{V}, \mathrm{Cr}$ and $\mathrm{Mn}$ whose ranges were below $0.15 \mathrm{mg} / \mathrm{L}$. However, the concentration of $\mathrm{Mn}, \mathrm{Fe}, \mathrm{Cu}, \mathrm{Zn}$, and $\mathrm{Pb}$ in soil and faunal muscles ranged between $0.46-914.0$ and $1.94-1863.0 \mu \mathrm{g} / \mathrm{g}$, respectively. The generated data suggests that anthropogenic activities and climate change effects exacerbate environmental pollution and health risks.
\end{abstract}

Key words: Biodegradable, Biodiversity, Ecosystem, Fauna and flora, Heavy metal and Pollution

\section{INTRODUCTION}

Effects of increased pollution in terrestrial and aquatic environments are rapidly growing. Among the pollutants are heavy metal contaminants discharged by domestic and industrial settings within the urban and peri-urban ecosystems. In Mombasa County, anthropogenic activities such as establishment of industrial plants, mangrove tree logging, subsistence crop production, house construction, fishing, solid waste disposal, discharge of effluents and coral stone harvesting are the main contributors of environmental degradation, especially along Tudor Creek ecosystem. Both solid and liquid wastes contain heavy metals that are harmful to both flora and fauna inhabiting the habitat [1]. The pollution effects are further aggregated by poor disposal systems that result in their bioaccumulation in the food chain [2]. Presence or absence as well as surveyed number of particular organisms can act as indicators of pollution levels. Direct measurements of pollution types and toxicity levels in environmental, flora and faunal samples are even stronger indicators of pollution level and extent. The extensive usage of heavy metals in industry qualifies them as major sources of toxicants in waste water. The nonbiodegradability of metal ions results in its accumulation in living organisms whose effect manifest in form of various disease.

Pollution level evaluation in soil and water samples is important as it has the potential of explaining environmental and human health risks. Changes in heavy metal concentration above acceptable levels whether due to natural or anthropogenic factors can significantly contribute to serious environmental and human health challenges [1]. The emergence of unplanned housing structures in Tudor Creek, Mombasa County that led to depletion of mangrove forests with a view of clearing agricultural land, building sites besides provision of construction materials as well as firewood have destabilized environmental conservation efforts. Further, effects of climate change have exacerbated anthropogenic activities with adverse effects on environmental sustainability of Tudor creek marine resources.

Anthropogenic activities particularly, crop production alongside the discharge of raw domestic and industrial effluents coupled up with agrochemical wastes have negatively impacted upon the floral and faunal biodiversity within the Tudor Creek ecosystem. The worst hit is the fishing industry that supports a large 
population of the ecosystem's human population. Generally, plants take up macro and micronutrients to support growth and development. Among the micronutrients are heavy metals such as $\mathrm{Cu}, \mathrm{Ni}, \mathrm{Zn}, \mathrm{Fe}$ and $\mathrm{Mn}$ that are usually taken up by plants and microorganisms in trace quantities so as obtain a balanced nutritional condition. In most marine ecosystems, mangrove forests act as sinks or buffers by removing or immobilizing heavy metals within the ocean beaches and aquatic environments [3]. When taken up in large amounts, heavy metals cause adverse effects on organisms through bioaccumulation [2].

Heavy metals such as Cd have been documented as serious causes of human health complications [4] while Arsenic is reported as an important cause of cancerous deaths and skin lesions. Additionally, it is responsible for high rates of miscarriages and premature delivery besides triggering neurological complications among human populations that have been reported elsewhere [4]. Chemicals such as $\mathrm{Pb}, \mathrm{Cd}, \mathrm{Hg}$ and $\mathrm{Ti}$ have no known nutritional value in plants; however, they are detrimental when taken up even in trace quantities [5]. The application of pesticides such Methyl parathion for crop protection not only affect insects but also human beings [6]. Trichloroethylene is a common degreasing agent used in the industry whose poor disposal may cause central nervous system impairment [7]. It is against this background that the study sought to investigate the types and levels of pollutants along Tudor Creek, besides the elucidation of floral and faunal biodiversity as indicators of environmental pollution levels and potential health risks resulting from bioaccumulation.

\section{MATERIALS AND METHODS}

The following materials and methods were deployed to achieve the above listed objectives.

\subsection{Site Description}

The study was performed along Tudor Creek in western Indian Ocean that extends between longitude $39^{\circ} 30^{\prime} \mathrm{E}$ and $39^{\circ} 45^{\prime} \mathrm{E}$ and latitude $3^{\circ} 4.5^{\prime} \mathrm{S}$ and $4^{\circ} 15^{\prime} \mathrm{S}$ (Fig. 1a). The Creek is situated between Mombasa Island and North Coast mainland along the magnificent western Indian Ocean. Old Town, Moroto and Mikindani were selected as study sites and plotted on the aerial map (Fig. 1b). Temperature range of the study area was $21^{\circ} \mathrm{C}$ and $35^{\circ} \mathrm{C}$, minimum and maximum, respectively. The average annual relative humidity was $77.6 \%$ while the average annual rainfall was $1162 \mathrm{~mm}$ [8]. It offers an ideal environment for studying processes underling anthropogenic and climatic change effects that influence human livelihood. The influx of rural - urban immigrants and subsequent settlement in the congested Mombasa city has resulted into rapid establishment and expansion of unplanned informal housing systems characterized by poor drainage systems that culminate into deplorable sanitation situation along the Creek. The Creek supports livelihoods of a large human population occupying Old Town, Kongowea, Buxton, Kisauni, Mishomoroni, Tudor, Moroto, Burukenge, Kibarani, Kenya Meat Commission, Bangladesh, Changamwe and Mikindani. Most inhabitants of the cited areas live in deplorable slum and survive on less than US\$ 1 per day.

\subsection{Anthropogenic Factors on Environmental Degradation}

Anthropogenic activities carried out along the Creek included, swimming, fishing, agriculture, construction, industrial processing among other socio-economic activities. The cited activities discharge huge waste into both terrestrial and aquatic environments within the ecosystem. Direct disposal of solid wastes and discharge of raw effluents into the aquatic environment influences creek water quality, dissolved oxygen concentration, turbidity and conductance that have a direct influence on marine and terrestrial life. The enumerated parameters alongside others contribute towards deterioration of the aquatic environment. The deforestation of mangrove plantations has equally negatively influenced Tudor Creek ecosystem. The study reports on negative impacts of both climate change and anthropogenic activities for enhanced sustainable livelihood with focus on floral and faunal biodiversity indices as indicators of the environmental pollution or sustainability. Essentially, microorganisms are key drivers of biogeochemical processes besides acting as biodegradation agents of pollutants.

\subsection{Faunal and Floral Biodiversity Estimates}

Four $50 \mathrm{~m}$ by $50 \mathrm{~m}$ transects adjacent to each off shore were identified for floral estimates while faunal diversity was estimated in four $2 \mathrm{~m}$ x $2 \mathrm{~m}$ transects located within each transect. Shannon Weiner Index of general diversity index $(\mathrm{H})$ [Equation 1] and dominance index $(\mathrm{C})$ [equation 2] were estimated:

$$
\begin{array}{ll}
\{\text { Equation 1\} } & \mathrm{H}=\sum_{i=l}^{s}(\mathrm{ni} / \mathrm{N}) \log _{2}(\mathrm{ni} / \mathrm{N}) \\
\text { \{Equation 2\} } & \mathrm{C}=\sum_{i=l}^{s}(\mathrm{ni} / \mathrm{N})^{2}
\end{array}
$$

In the above equations, ni is the importance value of each species represented by the number of individuals while $\mathrm{N}$ is the sum of the importance values and $\mathrm{s}$ is the summed taxa number [9]. 


\subsection{Soil /Water Sampling and Chemical Analysis}

Soil samples were collected from a depth of $0-15 \mathrm{~cm}$ using a clean plastic trowel in $2 \mathrm{~m}$ by $2 \mathrm{~m}$ preselected faunal estimate transects. The soil samples were kept in a polythene bag $(500 \mathrm{ml})$ while water samples were collected in $250 \mathrm{ml}$ plastic containers in four replicates from each site during the 2010-2011 wet and dry seasons. Soil samples were analyzed using Energy Dispersive X-ray Fluorescence (EDXRF) while water samples were analyzed using Total Reflection X-ray Fluorescence (TXRF) (Fig. 2). One gram of well mixed air dried soil samples from each site was weighed into a $120 \mathrm{ml}$ flask after grinding using pestle and mortar. Further grinding using Frisch Pulverischer type 02102 No. 3186 was performed and sieved through a $100 \mu \mathrm{M}$ mesh. Each of the $1 \mathrm{~g}$ soil samples was mixed and homogenized with $0.5 \mathrm{~g}$ cellulose binder in the ratio of 2:1. Three replicate pellets per sample measuring $2.5 \mathrm{~cm}$ diameter weighing between $400-500 \mathrm{mg}$ were prepared using manual hydraulic press. The pellets were kept at room temperature in readiness for irradiation before being subjected to standard analysis protocol. Water samples were filtered using Whatman No. 42 filter paper into clean $100 \mathrm{ml}$ conical flasks. $10 \mathrm{ml}$ of each sample was pipetted into a clean vial after which, $20 \mu \mathrm{L}$ of $1000 \mathrm{ppm}$ Gallium stock solution was added. Each sample was shaken for one minute to homogenize. Aliquots measuring $10 \mu \mathrm{L}$ of each sample was pipetted into clean oven dried quartz carrier. Each sample carrier was irradiated for 300 seconds using a S2PICOFOX TXRF molybdenum anode connected Spectrophotometer operated at $50 \mathrm{kV}$ at a current of $1000 \mu \mathrm{A}$. The measured spectra were used to estimate the concentrations of heavy metals (Fig. 2) based on S2PICOFOX software for specific elements by adopting [Equation 3] and [Equation 4] for water and soil sample analysis, respectively. Averages of the generated values were calculated. In addition, soil and water $\mathrm{pH}$ as well as conductance were measured using $\mathrm{pH}$ and conductance meters.

$\{$ Equation 3$\} \quad \mathrm{Cis}=\mathrm{N} x / \mathrm{S} x / \mathrm{Nis} / \mathrm{Sis} \mathrm{x} \mathrm{XCis}$

\{Equation 4$\} \quad \mathrm{Ci}=$ li/Si.Ai

\section{RESULTS}

The detection of significant levels of pollutants in environmental samples alongside faunal muscles is an indication of potential health risk (Table 1). The discharge of untreated domestic and industrial effluents into Tudor Creek impacted adversely upon floral, faunal and related conservation efforts undertaken in the ecosystem for a sustainable exploitation. The detection of chemical pollutants in water, soil as well as faunal muscles as demonstrated by X-ray fluorescence spectrum in the three sites is an indication of negative impact of human activities (Fig. 1b). The determination of significant concentrations of $\mathrm{Ti}, \mathrm{V}$ and $\mathrm{Cr}$ at $0.15 \mathrm{mg} / \mathrm{L}$ and Ni, $\mathrm{Cu}, \mathrm{Zn}, \mathrm{Pb}$ and $\mathrm{As}$ at concentrations around $0.05 \mathrm{mg} / \mathrm{L}$ in water are critical upon bioaccumulation though they remained below detection levels (Fig. 3). Fe concentrations were high in water samples while $\mathrm{Mn}, \mathrm{Zn}, \mathrm{Pb}$ and $\mathrm{Cu}$ concentrations were significant in soil samples (Fig. 4). Similarly, significant concentrations of $\mathrm{Ti}, \mathrm{V}$ and $\mathrm{Cr}$ at $0.15 \mathrm{mg} / \mathrm{L}$ were recorded in water samples alongside Ni, Cu, $\mathrm{Zn}, \mathrm{Pb}$ and $\mathrm{As}$ (Fig. 4). However, latter elements were below detection levels set at $0.05 \mathrm{mg} / \mathrm{L}$ for water samples. In addition, $\mathrm{Pb}$ and $\mathrm{Cr}$ were also undetectable at concentrations of $0.05 \mathrm{mg} / \mathrm{L}$ in fish and oyster muscles (Table 1). The presence of large amounts of Fe in faunal muscles especially among gastropods, crabs, oysters and fish presents a chance for micronutrient supplementation in human food since they are common protein sources (Fig. 5; Table 1). Cu was also detected

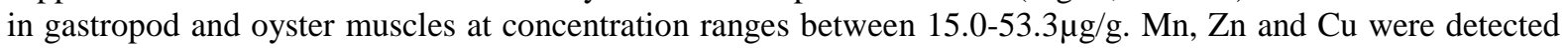
within a concentration range of 1.94-99.5 $\mu \mathrm{g} / \mathrm{g}$ in fish muscles. However, $\mathrm{Hg}, \mathrm{Cd}$ and $\mathrm{As}$ were not detected. The detection of significant heavy metal concentrations in both water and faunal muscles demonstrate the presence of large concentrations of heavy metal pollutants in the environment with great potential for bioaccumulation in the food chain [2].

The negative effects of climatic change coupled with anthropogenic activities are fast reducing the area covered by mangrove forests (Fig. 6a). The construction of informal settlements along the shoreline has the potential of causing natural hazards such as erosion, flooding, storm waves and surges (Fig. 6b). The loss of mangrove species such as Avicennia marina through logging for sale and clearing of sites for human settlement, agricultural activities and provision of firewood have greatly contributed towards coastal water quality reduction besides endangering the biodiversity of endemic faunal species. The elimination of both fish and crustacean nurseries and breeding habitats that normally exist within mangrove forests may potentially affect human socioeconomic well being. Fishes, crustaceans, mollusks, nematodes, insects and birds were significant members of the faunal group within the study sites. Crabs were the most abundant ground inhabiting organisms accounting for $40 \%$ followed by oysters that comprised $25 \%$ while gastropods made up only $15 \%$ (Fig. 7). Fishes represented by Lutjanus argentimaculatus and Gymnocranius elongates alongside oyster species such as Crassostrea gigas and crabs represented by Goetice depressa and Leptodius exaratus are among the dominant groups harvested and marketed income generation besides critical sources of proteins (Fig. 5). The study 
revealed that crabs were the most abundant faunal group accounting for $40 \%$ followed by oysters that comprised $25 \%$ while gastropods made up $15 \%$.

Alongside the restoration of marine life, mangroves are a major resource of income for the local inhabitants. The mangroves provide building poles, timber for boat construction as well as firewood among other uses. These activities were evidenced through the rampant mangrove logging along the Creek. Mikindani had the highest floral species diversity that accounted for $60 \%$. R. mucronata was the most diverse with an index of 0.75 and 0.57 for Mikindani and Moroto, respectively (Table 2). The corresponding dominance indices were 3.674 and 1.853, respectively. C. tagal was present only in Mikindani with diversity and dominance indices of 0.33 and 0.0048 , respectively. C. tagal was uniquely found inhabiting transects furthest from shoreline while $R$. mucronata and $S$. alba predominated the shoreline. The biodiversity index of $C$. tagal in transect next to shoreline was 0.36 with adjacent transects recording 0.29 . S. alba accounted for $0.02 \%$ and $0.4 \%$ of Mikindani and Moroto mangrove populations, respectively (Fig. 8). A. marina suffered losses due to logging and its exploitation resulted into large areas of mangrove forest depletion (Fig. 6a). It was also more dominant in Moroto with an index of $8.55 \times 10^{-1}$ while Mikindani had $4.00 \times 10^{-6}$. Comparison of diversity indices revealed that A. marina was more diverse in Moroto (0.36) than Mikindani (0.09). However, $R$. mucronata was the most desirable mangrove species for silvicultural practices and reforestation activities because of its fast growth and viviparous seeds (Fig. 8). Different non- and biodegradable solid wastes were recorded. The highest proportion of solid wastes reported in Mikindani comprised of dry twigs and leaves with a negligible number of polythene bags as well as plastic bottles. Solid wastes in Moroto were predominated by plastic bags and bottles whereas Old Town recorded the highest number of solid wastes comprising of plastic bottles, old vehicle tyres, clothes and sandals (Fig. 9).

\section{DISCUSSION}

Pollutants in environmental samples present a great health risk to human beings. Besides this, heavy metal contamination has devastating effects on terrestrial ecological balance as well as diversity of aquatic organisms [5]. The fishing industry is critical since it provides fish, a known source of proteins besides being a source of income and thus plays an important role in socioeconomic empowerment for livelihoods among Creek inhabitants. The detection of high concentrations of heavy metal in faunal muscles consumed as delicacies present potential health risk among the inhabiting population. Concerns regarding nutritional provision while guarding against bioaccumulation of heavy metals in aquatic organisms inhabiting polluted environments have similarly been expressed by Narayanan [10]. The high concentrations of Fe recorded in gastropod muscles has potential of being used as a nutritional supplement, especially among expectant mothers and children. Elsewhere, attempts have been made to use aquatic organisms like fishes and sea dwelling birds such as Calomectris diomedia as biomarkers through tracking of specific indicators to monitor heavy metal pollution $[11,12]$.

The clearing of mangroves hamper flourishing of marine life that include fishes, crustaceans and mollusks. Estimates of the annual economic value of mangroves have been made based on the cost of products and services they provide [9]. By 2006, the cost of mangrove products and services were estimated to be within the range of US\$ $200,000-900,000 \mathrm{ha}^{-1}$ [13]. Elsewhere, the cost of mangrove restoration has been estimated to be about USD $225-216,000 \mathrm{ha}^{-1}$. This cost was exclusive of the cost of land for mangrove restoration [14]. The value of mangroves based on storm protection and flood control in Malaysia was estimated to cost US\$ $300,000 \mathrm{~km}^{-1}$ of coastline. This cost was based on the replacement of mangroves with rock built walls to guard against stormy waves and flooding. The value of mangroves on Moreton bay in Australia was valued at US\$ $4,850 \mathrm{ha}^{-1}$ based on the catch of marketable fish [15]. Findings on biomass accumulation from mangrove inhabited sites are supported by those of Mumby et al. [16] who reported that marine flora have the potential of enhancing biomass of coral reef aquatic life and fish communities in the Caribbean.

Mangrove ecosystems are considered highly productive by functioning remarkably well in various ecological processes and climate change mitigation. This consideration has been underscored through the identification of desirable species with silvicultural practices for reaforestration as has been demonstrated at the Mikindani site. Similar attempts were made in Thailand where it was reported that the cost of mangrove restoration amounted to US\$ $946 \mathrm{ha}^{-1}$ while the cost of protecting existing mangroves was US\$ $189 \mathrm{ha}^{-1}$ [14]. It is also worth noting that mangrove ecosystems have the capacity to act as a sink or buffer to remove or immobilize metals. Mangrove species like $R$. mucronata could have played a critical role in phytoremediation of the Mikindani site, thus resulting into low heavy metal concentrations in both soil and water samples. Notwithstanding the above, mangroves have the potential of mitigating climatic changes by acting as carbon sinks through carbon sequestration. The value of mangroves can be estimated based on the cost of restoring or enhancing coverage of deforested shoreline. A pilot reforestation programme has been initiated through this study at Mikindani to conserve $R$. mucronata mangrove trees. Due to the demonstrated high value of mangroves, an attempt to initiate a planting program at the Mikindani site was undertaken during the research 
project implementation period. Mangrove loggers within the ecosystem are a potential threat to mangrove conservation efforts besides negatively affecting the aquatic life breeding habitats.

Establishment of informal settlements resulted into open sewage systems with negative effects on ecological balance and human health (Fig. 6a). Some of the open sewage systems were exploited for agricultural crop production because of the high plant nutritional resources emanating from the decomposing organic matter. Besides the raw effluents being sources of environmental pollution, they provided possible suitable breeding sites for disease causing vectors like mosquitoes that transmit malaria. It is also known that microbes play a critical role in remediation of environments infested with high concentrations of heavy metals [17, 18]. Deployment of both plants and organisms especially bacteria in an attempt to break down pollutants to usable nutrients while converting them to less harmful forms for plant uptake is a bioremediative scientific pathway that is quite noble and offers a great promise for future applications [19]. The detection of Pseudomonas in soil sampled from Moroto that also exhibited high concentrations of heavy metals demonstrated some level of correlation which led to the speculation that the organisms could have played a major role in the detoxification of chemical pollutants. the non-biodegradability of metallic ions results in its accumulation in living organisms.

Elsewhere, radiation resistant bacteria such as Deinococcus radiodurans are reported to be used in cleaning of environments contaminated with toxic radioactive wastes [20]. The development of biotechnologically modified Pseudomonas putida by incorporating both mercury detoxifying and toluenedegrading genes as bioremediative agents has also been reported [4]. It is worth noting that two gastrointestinal bacterial species, Escherichia coli and Enterococci were also recorded in Moroto water samples. It was noted that raw domestic sewage loaded with human fecal material was discharged directly into the ocean water. The water quality signified by high turbidity values, low dissolved oxygen as indicators of stressful aquatic environment. Essentially, biochemical oxygen demand (BOD) values which reflect measurements of biodegradable organic pollutants in aqueous samples are good indicators of pollutant concentrations in water bodies $[21,22]$. It is worth noting that water quality determined by $\mathrm{pH}$, turbidity, dissolved oxygen, conductivity and other physico-chemical parameters generally influence faunal and floral biodiversity. It is apparent that both human activities as well as climate change effects impacted adversely on Tudor Creek ecosystem.

\section{CONCLUSION}

The study revealed that Tudor Creek is rich in faunal and floral biodiversity. However, the rich Tudor Creek ecosystem biodiversity is threatened by anthropogenic activities coupled up with climatic change effects. Heavy metal concentrations detected in water, soil, crustacean, mollusk and fish muscles suggest that anthropogenic activities and climate change effects exacerbate environmental pollution and human health risks through bioaccumulation. The impacts of both factors adversely affect environmental conservation efforts for enhanced exploitation and sustainability. The corollary effect of the interactions is expressed in socioeconomic endeavors and livelihoods of the Creek's inhabitants. It is therefore necessary to initiate a well coordinated and concerted environmental pollution monitoring and surveillance effort to enhance biodiversity conservation through reduced pollution.

\section{Acknowledgements}

The authors wish to thank Ms. Monicah Koinange, Mr. Edwin Matoka and Mr. Ali Kanga for their technical assistance. The financial support provided by the National Council for Science and Technology (NCST) through Research Grant No.: NCST/5/003/0396 is sincerely appreciated.

\section{FIGURES AND TABLES}

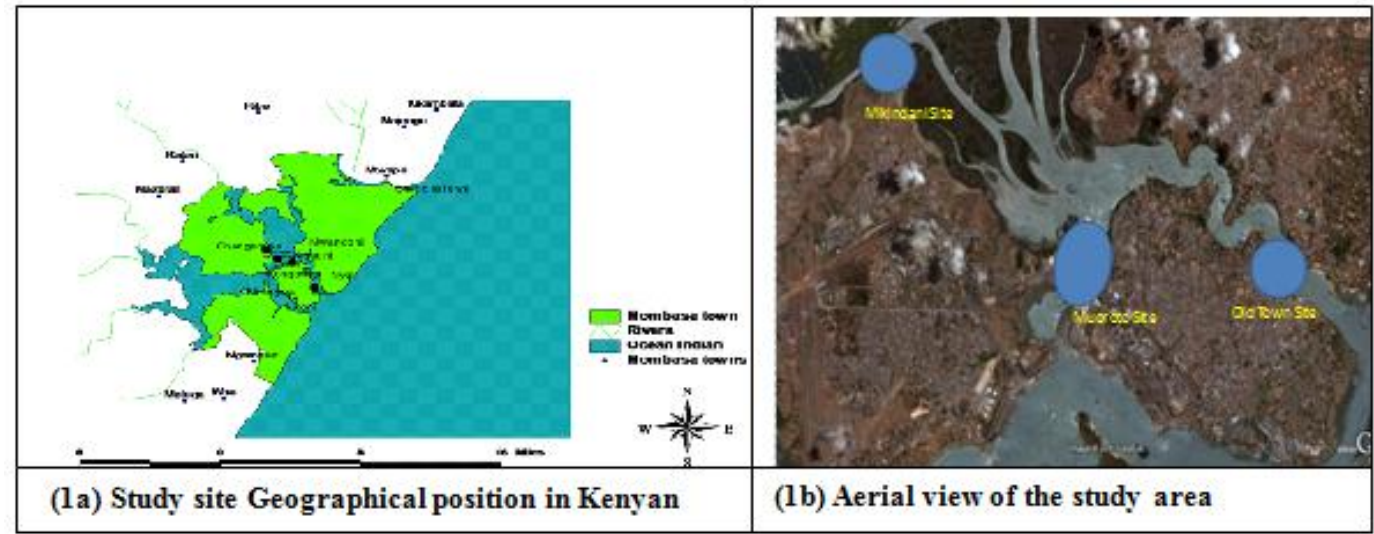

Fig. 1: Google maps showing (a) geographical location and (b) aerial view of Tudor Creek 


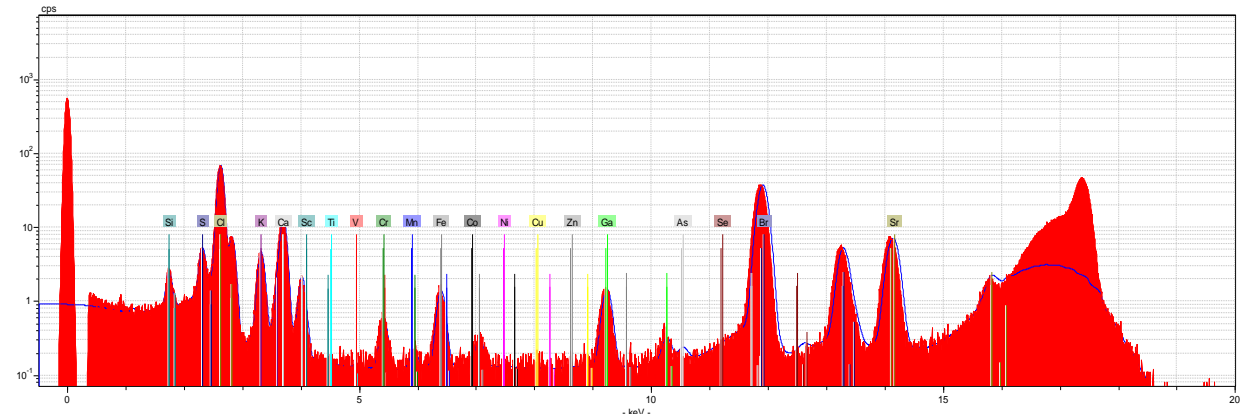

Fig. 2: Typical TXRF spectrum (log scale) for heavy metal detection in water samples

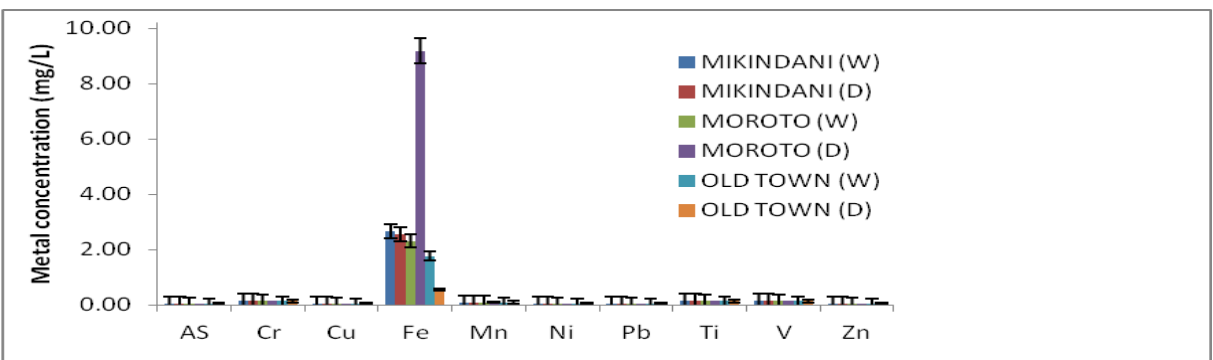

Fig. 3: Heavy metal concentrations in water samples during wet (w) and dry (d) seasons

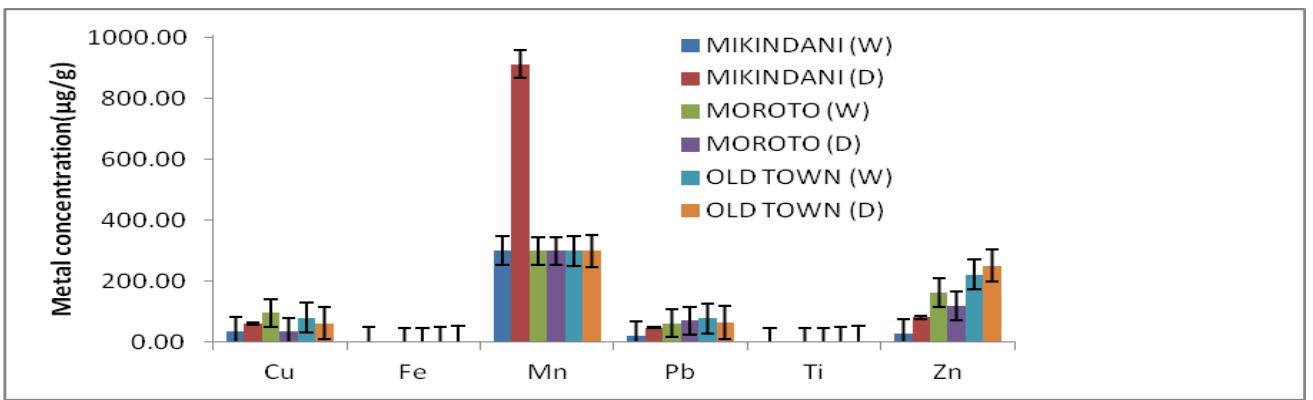

Fig. 4: Heavy metal concentrations in soil samples during wet $(w)$ and dry (d) season

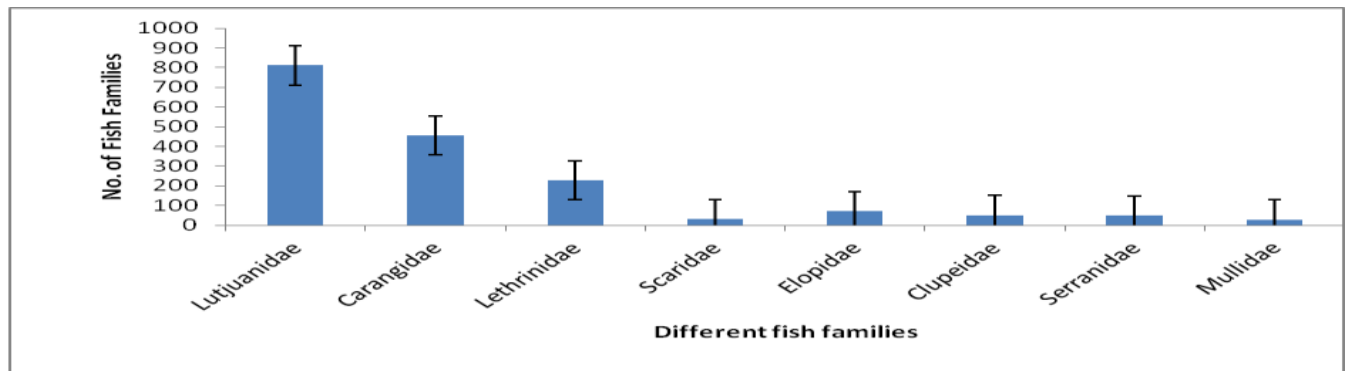

Fig. 5: Marketable fish families identified from catches made within Tudor Creek Study site

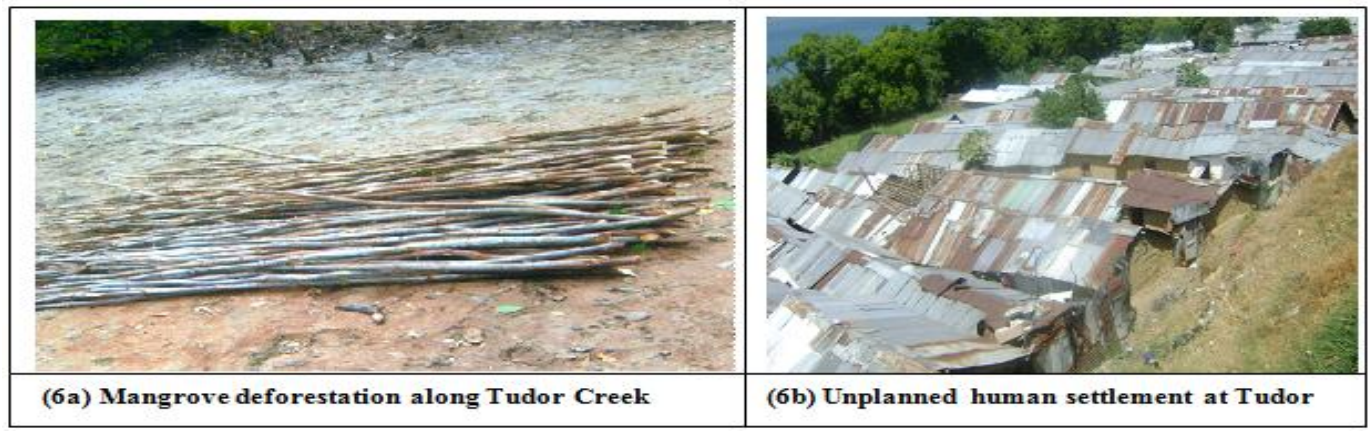

Fig. 6: Photographs capturing mangrove deforestation and unplanned settlement at Tudor 


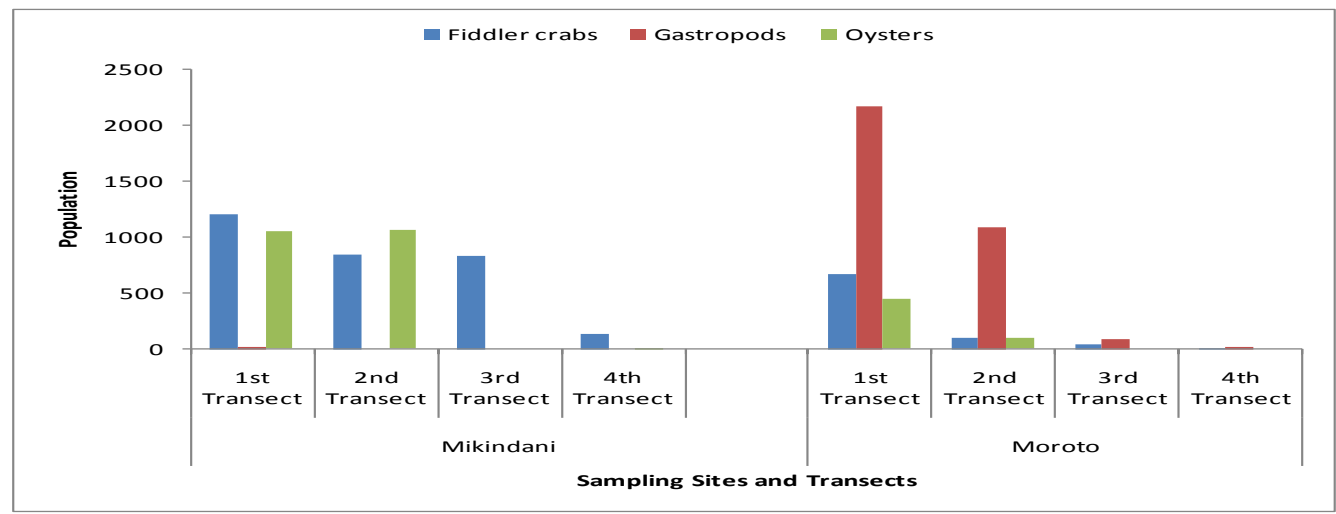

Fig. 7: Faunal biodiversity estimates within the four transects at Mikindani and Moroto sites

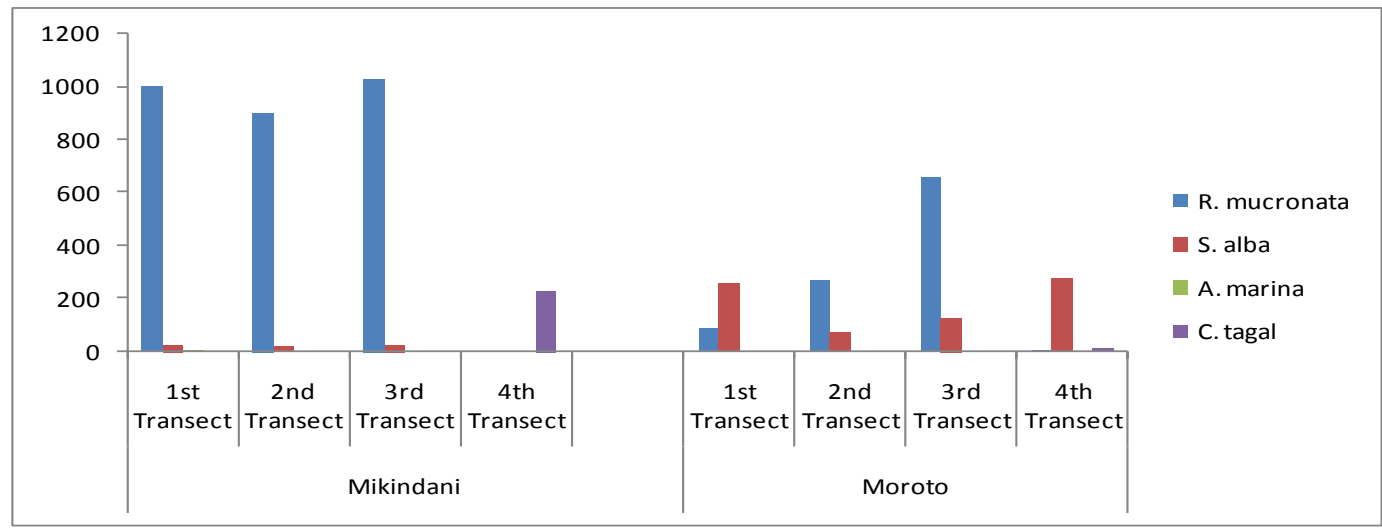

Fig. 8: Mangrove population surveyed within four transects at Mikindani and Moroto sites

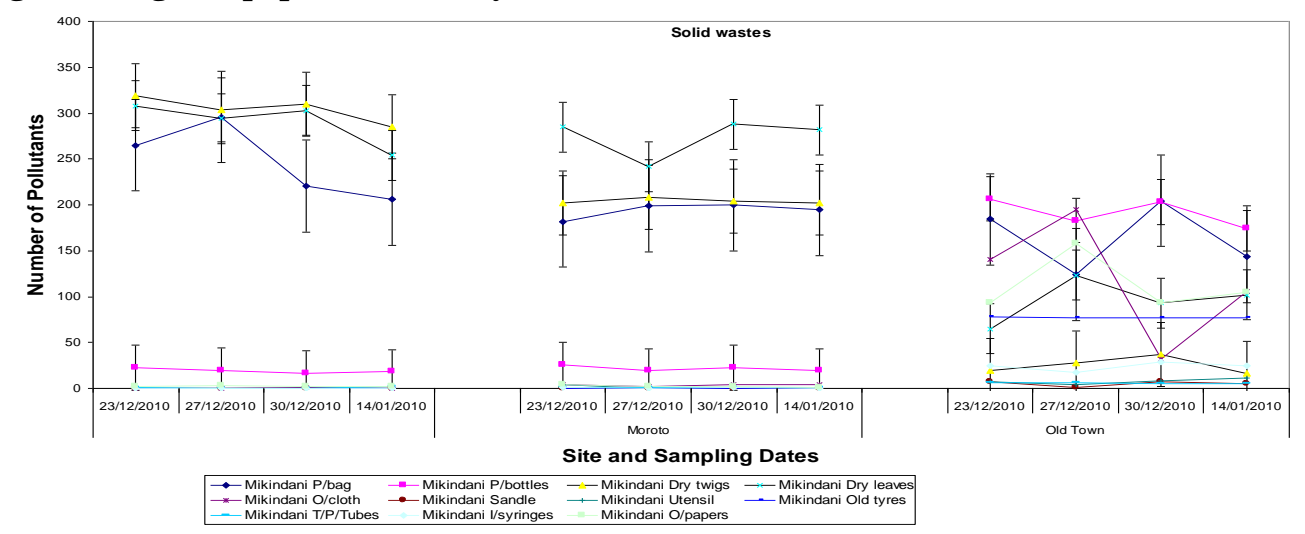

Fig. 9: Proportion of biodegradable and non-biodegradable solid wastes from the study sites Table 1: Heavy metal bioaccumulation in faunal muscles $(\mu \mathrm{g} / \mathrm{g})$

\begin{tabular}{clllllllll}
\multicolumn{8}{c}{ Table 1: Heavy metal bioaccumulation in faunal muscles $(\boldsymbol{\mu g} / \mathbf{g})$} \\
\hline Fauna & & $\mathbf{C u}$ & $\mathbf{C r}$ & $\mathbf{F e}$ & $\mathbf{M n}$ & $\mathbf{P b}$ & $\mathbf{T i}$ & $\mathbf{Z n}$ \\
\hline Crustacean & Fiddler crab & $53.3 \pm 1.2$ & $<0.10$ & $1863 \pm 26.0$ & $31.4 \pm 1.20$ & $<0.05$ & $71 \pm 2.60$ & $38.4 \pm 0.90$ \\
& Prawn & $33.8 \pm 0.80$ & $7.94 \pm 1.0$ & $257.0 \pm 130$ & $4.13 \pm 0.86$ & $<0.05$ & $9.7 \pm 1.66$ & $24.7 \pm 0.69$ \\
\multirow{5}{*}{ Fish family } & Carangidae & $<0.05$ & $<0.10$ & $96.7 \pm 1.80$ & $1.94 \pm 0.71$ & $<0.05$ & $3.31 \pm 1.40$ & $14.0 \pm 0.52$ \\
& Lethrinidae & $<0.05$ & $<0.10$ & $386.0 \pm 9.0$ & $22.8 \pm 3.10$ & $<0.05$ & $34 \pm 5.40$ & $19.6 \pm 1.50$ \\
& Lutjanidae & $<0.05$ & $<0.10$ & $157.0 \pm 3.5$ & $3.81 \pm 0.93$ & $<0.05$ & $7.66 \pm 1.87$ & $11.8 \pm 0.63$ \\
Mollusks & Gastropod & $21.5 \pm 1.0$ & $65.3 \pm 2.9$ & $721.0 \pm 13.0$ & $8.33 \pm 1.34$ & $<0.05$ & $37.9 \pm 3.20$ & $10.6 \pm 0.70$ \\
& Oyster & $15.0 \pm 1.10$ & $<0.10$ & $461.0 \pm 8.0$ & $17.1 \pm 1.90$ & $<0.05$ & $31.5 \pm 3.70$ & $406.0 \pm 15.0$ \\
\hline
\end{tabular}


Heavy Metal Bioaccumulation as Indicators of Environmental Pollution and Health Risks

Table 2: Mangrove species distribution among transect, where (-) denotes non-existence

\begin{tabular}{lllllllll}
\hline & Mikindani & \multicolumn{7}{c}{ Moroto } \\
& $\begin{array}{l}\text { Rhizophora } \\
\text { mucronata }\end{array}$ & $\begin{array}{l}\text { Ceriops } \\
\text { tagal }\end{array}$ & $\begin{array}{l}\text { Avicennia } \\
\text { marina }\end{array}$ & $\begin{array}{l}\text { Sonnerata } \\
\text { alba }\end{array}$ & $\begin{array}{l}\text { Rhizophora } \\
\text { mucronata }\end{array}$ & $\begin{array}{l}\text { Ceriops } \\
\text { tagal }\end{array}$ & $\begin{array}{l}\text { Avicennia } \\
\text { marina }\end{array}$ & $\begin{array}{l}\text { Sonnerata } \\
\text { alba }\end{array}$ \\
\hline $1^{\text {st }}$ Transect & 0.76 & 0.36 & - & 0.28 & 0.76 & - & 0.05 \\
$2^{\text {nd }}$ Transect & 0.76 & 0.29 & 0.09 & 0.18 & 0.69 & - & 0.11 & - \\
$3^{\text {rd }}$ Transect & 0.75 & - & - & 0.34 & 0.43 & - & 0.62 & 0.2 \\
$4^{\text {th }}$ Transect & 0.74 & - & - & 0.1 & 0.39 & - & 0.64 & - \\
\hline
\end{tabular}

\section{REFERENCES}

[1] M.I Yahaya, S. Mohammad and B.K. Abdullahi, Seasonal Variations of Heavy Metals Concentration in Abattoir Dumping Site Soil in Nigeria. Journal of Applied Science and Environmental Management, 13(4), 2009, 9-13.

[2] P. Szefer, K. Ikuta, S. Kushiyama, K. Frelek and J. Geldon, Distribution of trace metals in the Pacific oyster, Crassostrea gigas. and Crabs from, the East Coast of Kyusha Island. Japanese Bulletin of Environmental Contamination Toxicology, 58, 1997, $108-114$.

[3] V. Pahalawattaarachchi, C.S. Purushothaman and A. Vennila, Metal phytoremediation potential of Rhizophora mucronata (Lam.). Indian Journal of Marine Sciences, 38(2), 2009, 178-183.

[4] J.O. Duruibe, M.O.C. Ogwuegbu and J.N. Egwurugwu, Heavy metal pollution and human biotoxic effects. International Journal of Physical Science, 2(5), 2007, $112-118$.

[5] E.O. Farombi, O.A. Adelowo, Y.R., Ajimoko, Biomarkers of oxidative stress and heavy metal levels as indicators of environmental pollution of African Cat fish (Clarias gariepinus) from Nigeria Ogun river. International Journal of Environmental Research in Public Health, 4(2), 2007, 158-165.

[6] J. Kumar and S.F. D’Souza, An optical Microbial Biosensor for Detection of Methyl Parathion Using Sphingomonas sp. Immobilized on Micro plate as a Reusable Biocomponent. Biosensors and Bioelectronics, 26(4), 2010, 1292 - 1296.

[7] M. Hnaien, S. Bouriga, F. Besseueille, J. Bausells, A. Errachid, F. Lagarde and N. Jaffrezic-Renault, Impedimetric Microbial Biosensor Based on Single Wall Carbon Nanotube Modified Electrodes for Trichloroethylene Detection. Electrochimica Acta, $56(28), 2011,10353-10358$.

[8] Mombasa Island weather website: http://www.climatetemp.info/kenya/mombasa.html accessed on 17th March, 2011

[9] J.I.N. Kumar, R.N. Kumar, R.K. Bhoi and P.R. Sajish, Tree species diversity and soil Ecology, $51(2), 2010,273$ - 279.

[10] E.L. Gilman, J. Ellison, N.C. Duke and C. Field, Threats to mangroves from climate change and adaptation options. Aquatic Botany, 2097, 2008, 1-14

[11] R.V. Narayanan, Bioaccumulation of heavy metals in organs of fresh water fish Cyprinus carpio (Common carp). International Journal of Environmental Science and Technology, 5(2), 2008, 179-182.

[12] A. Renzoni, S. Focardi, C. Fossi, C. Leonzio and J. Mayol, Comparison between concentrations of mercury and other contaminants in eggs and tissues of Cory's Shearwater Islands. Environmental pollution, 40, 1986, 17-35.

[13] S. Wells, C. Ravilous and E. Corcoran, In the Front Line: Shoreline Protection and Other Ecosystem Services from Mangroves and Coral Reefs. United Nations Environment Programme, World Conservation Monitoring Centre, Cambridge, UK, 2006.

[14] R.R. Lewis, Ecological engineering for the successful management and restoration of mangrove forest. Ecological Engineering, 24, $2005,403-418$

[15] Ramsar Secretariat, Wetland Values and Functions: Climate Change Mitigation. Gland, Switzerland, 2001.

[16] P. Mumby, A. Edwards, J. Arlas-Gonzalex, K.Lindeman, P. Blackwell, A. Gall, M. Gorczynaska, A. Harbone, C. Pescod, H. Renken, C. Wabnitx, G. Llewellyn, Mangroves enhance the biomass of coral reef fish communities in the Caribbean. Nature, 427 , 2004, 533-536.

[17] M.R. Bruins, S. Kapil and F.W. Oehme, Microbial resistance to metals in the environment. Ecotoxicology Environment Safety, 45, 2000, 198-207.

[18] R. Chouari, D. Le Paslier, P. Daegelen, P. Ginestet, J. Weissenbach and A. Sahir, Molecular evidence for Planctomycete diversity in a municipal wastewater treatment plant. Applied Environmental Microbiology, 69(12), 2003, 7354-7363.

[19] G.L. Challis, Mining microbial genomes for new natural products and biosynthetic pathways. Microbiology, 154, 2008, $1555-1569$.

[20] F. Wolfe-Simon, J.S. Blum, T.R. Kulp, G.W. Gordon, S.E. Hoeft Pett-Ridge, J.F. Stolz, S.M. Webb, P.K. Weber, P.C.W. Davies, A.D. Anbar and R.S. Oremland, A bacterium that can grow by using arsenic instead of phosphorus, 2010.

[21] Y. Lei, W. Chen and A. Mulchandani, Microbial Sensor. Analytica Clinica Acta, 568, 2006, 200 - 210.

[22] C. Dai and S. Choi, Technology and Applications of Microbial Biosensor. Open Journal of Applied Biosensor, $2,2013,83$ - 93. 